\title{
EL TALLER DE LAS ESTATUAS TOGADAS DE RONDA DE TEJARES (CÓRDOBA)
}

\author{
POR \\ ISABEL M. ${ }^{a}$ LÓPEZ LÓPEZ \\ Universidad de Córdoba
}

\section{RESUMEN}

En este artículo presentamos un conjunto de once estatuas togadas de plena época claudia procedentes de Colonia Patricia. Sus características estilísticas y sus rasgos de factura nos permiten identificarlas como producción de un mismo taller escultórico. Asimismo la calidad, dimensiones y material contribuyen a interpretarlas como representaciones de miembros de la dinastía julioclaudia, o bien de summi viri, siendo ubicadas en uno de los principales espacios públicos de la ciudad.

\section{SUMMARY}

The style and carving technique of a group of eleven togate statues dating to the reign of Claudius I from Colonia Patricia point to their being the product of a single workshop. The quality of the workmanship, their size, and the choice of material suggest that the sculptures were either of members of the Julio-Claudian dynasty or of summi viri, an interpretation reinforced by their location in one of the colony's principal public spaces.

\section{INTRODUCCIÓN}

La cuestión de los talleres escultóricos es problemática por diversas causas, entre las que destaca el anonimato de sus escultores. Dicha situación no es privativa de la producción escultórica cordobesa ${ }^{1}$ sino que se extiende a otros núcleos como Italica y Tarraco, conociéndose sólo la autoría del conjunto de togados procedentes del «Foro de Mármol» de Emerita Augusta ${ }^{2}$. Por lo tanto, son las esculturas mismas, en la mayoría de los casos, la principal fuente de información.

En la Bética podemos seguir el desarrollo de los talleres locales ${ }^{3}$ remontándonos al siglo I a.C., al

\footnotetext{
1 En Colonia Patricia sabemos de la existencia de dos talleres escultóricos en época flavia y en el siglo II d.C. (CIL II $/ 7, n^{\circ} 301, n^{\circ} 348$ ) junto a otros que elaboran capiteles desde la segunda mitad del siglo I d.C. hasta el siglo Iv d.C. (Márquez, 1993, 213-219).

2 Estos cinco togados conservan la firma de su oficina, el taller de C AI AVLI (Trillmich, 1990, 312-318; 1993, 50-53, Abb. 7-9; Rodá, 1996, 114).

3 Para esta evolución de los talleres locales de la Bética, consultar León, 1990, 367-380; Rodá, 1996, 105-141; para la retratística, León 1993, 11-21.
}

impacto y a la adaptación de los patrones itálicos por parte de los escultores prerromanos, como se documenta en el taller de Urso Colonia Iulia Genetiva (León, 1990, 369). Con la llegada del Imperio, se continúa por parte de algunos talleres con el empleo de la caliza, pero interpretando los modelos escultóricos de principios de época imperial, como es el caso de las esculturas femeninas tipo «Fundilia» del Museo de Arqueológico de Sevilla (León, 1995, 62-63). El esplendor se impone en los talleres a partir de época augústea, momento en el que se extiende el uso del mármol y se realizan obras de la calidad de la «Servilia» de Carmona y del togado de Carteia (León, 1990, 372, Taf. 43.a-b), y que proseguirá durante la dinastía julioclaudia. Posteriormente, durante el siglo II d.C. destaca la importancia y el estilo alcanzado por los talleres de Itálica (León, 1995, 26-28).

Por lo que se refiere a Córdoba, el análisis estilístico de las piezas nos ha permitido definir los rasgos que caracterizan el trabajo de un taller cuya producción abarca una serie de once togados de plena época claudia.

\section{LOCALIZACIÓN DE LAS ESTATUAS}

Extramuros de la ciudad romana, a escasos metros de la muralla norte, en la Avda. Ronda de Tejares, $n^{\circ}$ 38-40, esquina con Avda. de Cervantes, se halló una serie de once esculturas togadas ${ }^{4}$, cuyo contexto arqueológico quedó sin ver en el momento del hallazgo ${ }^{5}$. El estado de conservación de las pie-

\footnotetext{
${ }^{4}$ De este mismo solar procede posiblemente otra escultura togada datada por nosotros a mediados del siglo II d.C. (López, 1997, 109-111, nº cat. 35, lám. XXXIII, A-D). Su localización es dudosa, según A. M. Vicent, ya que fue requisada por las autoridades en un vacie de la ciudad (Expediente $\mathrm{n}^{\circ} 135$ del Museo Arqueológico Provincial de Córdoba).

${ }^{5}$ En este solar se realizó con posterioridad una intervención arqueológica por A. M. Vicent (Marcos-Vicent, 1983, $244, n^{\circ} 89$ ) donde se hallaron restos de un espacio doméstico con dos mosaicos, uno de tema báquico fechado entre el siglo II y principio del siglo III d.C. (Moreno, 1995, 160-161) y abundante material cerámico romano y medieval, junto a fragmentos de decoración arquitectónica.
} 


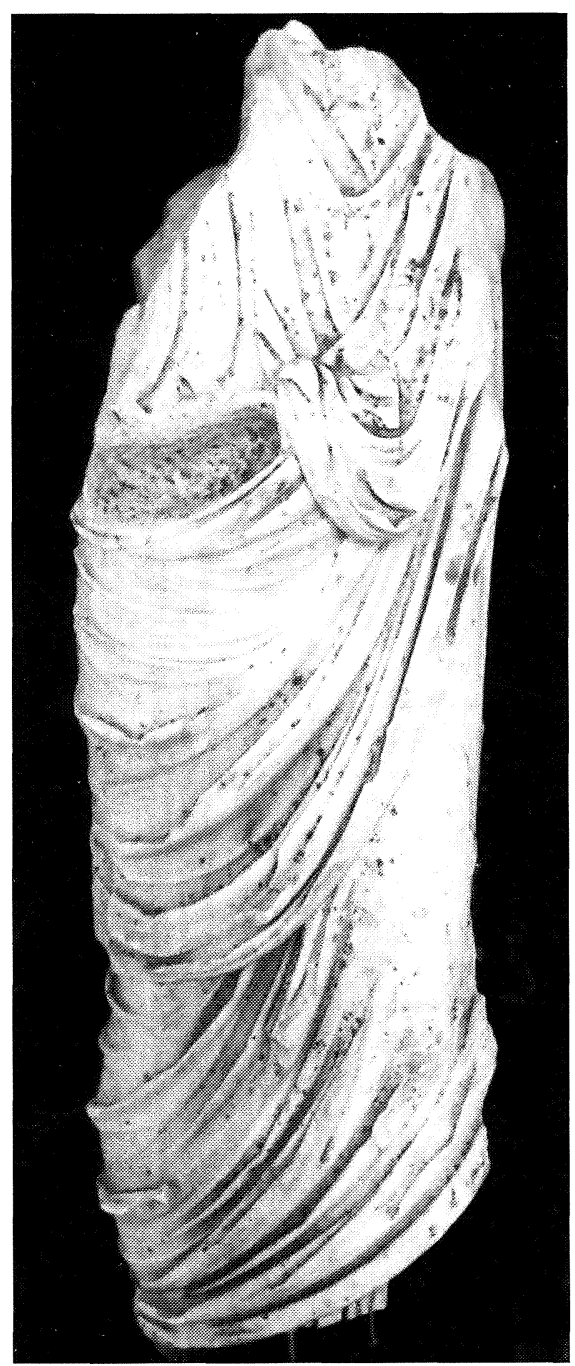

Figura 1.-Estatua togada $\mathrm{n}^{\circ}$ 1. Parte anterior. (Foto: A. Montejo).

zas y las fracturas intencionadas ${ }^{6}$ que en ellas se observan permiten plantear la hipótesis de que los togados fueron en un momento determinado acarreados a este lugar para su desmembramiento, probablemente, desde un importante espacio de la ciudad romana, quizás el foro colonial.

\section{LAS ESTATUAS}

Este conjunto de once togados ${ }^{7}$ se encuentran labrados en mármol italiano, probablemente de las

\footnotetext{
${ }^{6}$ Dichas fracturas se observan, por ejemplo, en los toga$\operatorname{dos} n^{\circ} 5,6$ y 8 .

Se hallan depositadas en el Museo Arqueológico Provincial de Córdoba con los siguientes $\mathrm{n}^{\circ \mathrm{s}}$ de inventario:
}

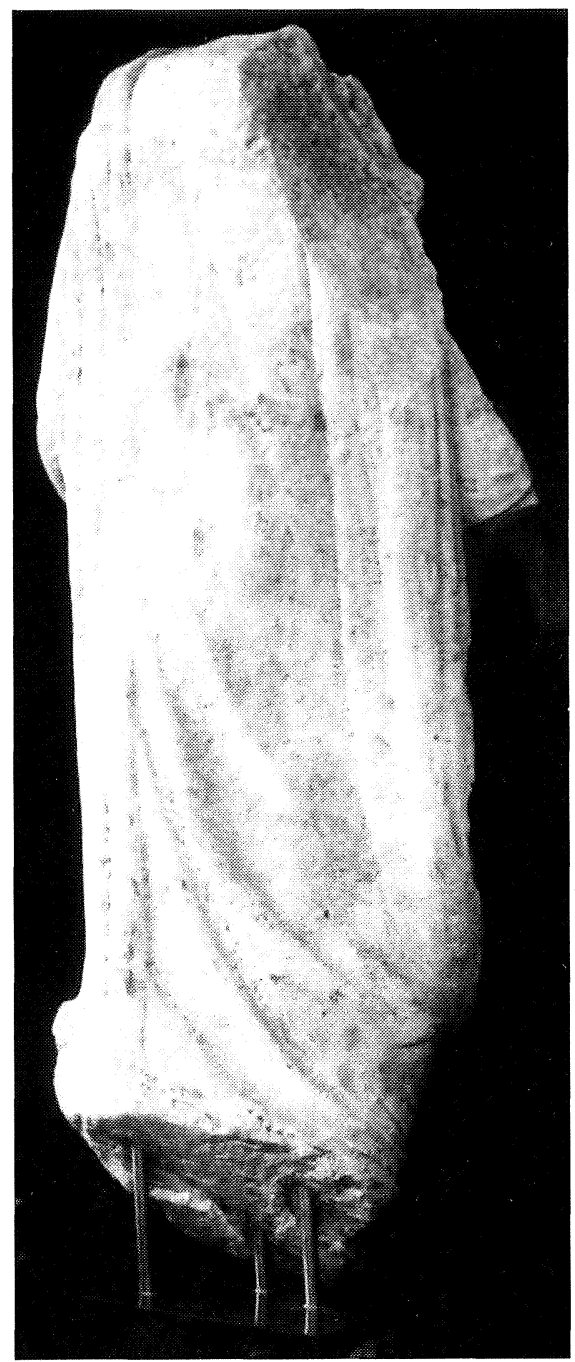

Figura 2.-Estatua togada $\mathrm{n}^{\circ} 1$. Parte posterior. (Foto: A. Montejo).

canteras de Luni; la importación de este material y su calidad, junto al formato de las estatuas, superior al natural, son elementos indicativos de su importancia y carácter.

\section{Estatua togada $n^{o} 1$ (fig. 1-2)}

Se halla fracturada en su parte derecha encima del balteus, en todo el lateral izquierdo y en la superior, quedando restos del hueco para la inserción

$29048,29049,29051,29047,29107,29046,29106,29104$ 29105, 29109, 29108, respectivamente. Sobre estas esculturas vid. Baena y Morena, 1989, 46-51; Marcos y Vicent, 1983, 244; López, 1996, 40-43; id. 1997, 61-83, ns cat. 14 24, lám. XVI-XXII. 
de la cabeza. La parte inferior también está incompleta y la parte posterior presenta múltiples roturas intencionadas. El estado general de conservación de la escultura es muy aceptable. En la zona central del lado izquierdo se conserva un hueco destinado a encajar parte del balteus, en cuya superficie se aprecian las huellas del trabajo del puntero para mejor ajuste de esta pieza, al igual que en la parte posterior, para el ensamblaje de la pieza correspondiente a los pliegues longitudinales. Sus dimensiones máximas son: altura $1,52 \mathrm{~m}$; anchura $0,45 \mathrm{~m}$; antero-posterior: $0,43 \mathrm{~m}$.

El esquema seguido para el tratatamiento de los paños responde al típico de: a) túnica con escote, que se dispone sobre el pecho en un plegado en forma de $« \mathrm{~V} »$ y es presionada en la cintura por el balteus dando lugar a tres pliegues curvilíneos que sobresalen del plano de la escultura; b) umbo formado por un conjunto de pliegues anchos, irregulares, con forma de «U» y ligeramente apuntados, que ocupan la parte central del tronco de la estatua y sobresalen prominentemente; c) sinus que cae por encima de la pierna derecha, procedente del hombro izquierdo, en pliegues profundos y espaciados, curvándose a la altura de la rodilla y subiendo en línea recta por el costado derecho; en su interior los pliegues, ligeramente curvos, quedan adheridos a la pierna derecha, dejando entrever su forma. Destaca el tratamiento del tejido correspondiente a la ima toga que permite, mediante un plegado muy suave, entrever la forma anatómica de la pierna izquierda, al igual que ocurre con la derecha bajo el sinus. Entre ambas piernas los pliegues de la ima toga se hacen más numerosos y profundos.

La ponderación de la escultura se aprecia a través de la posición de las piernas cubiertas por la toga; al igual que las otras esculturas de la serie se mantiene la pierna izquierda erguida, sirviendo de sostén, y la derecha, ligeramente flexionada y llevada hacia atrás, se observa en la parte posterior y anterior de la escultura.

Los pliegues de la toga han sido elaborados excelentemente por el artista, siendo marcados y profundos, definidos por gruesas aristas; en la parte posterior están más superficialmente trabajados, pero sin descuidar su factura. El escultor local ha realizado el plegado de la túnica ancho y espaciado, simplificando así la labra en esta parte de la pieza. Destaca el minucioso trabajo que queda plasmado en los contrastes realizados mediante la labor del trépano en los pliegues de la túnica y de la toga, anchos y espaciados, definidos por gruesas aristas que contribuyen a un efecto de claroscuro en el tejido. En esta escultura y en las siguientes destaca la plasticidad de los paños que se adaptan perfectamente a la superficie del cuerpo, ya sea a través de un plegado abundante, como se aprecia en el sinus, tanto en la parte anterior como en lateral derecho, o con pliegues escasos y finos en la ima toga que hacen que la tela transparente la epidermis, como se aprecia en la cadera y pierna izquierda. Esta suavidad del modelado confiere a las piezas una calidad acorde al estilo depurado y elegante que se proclama a partir de la época de Augusto (León, 1990, 372).

\section{Estatua togada $n^{\circ} 2$ (fig. 3-4)}

Se conserva el torso y parte de las piernas, con fractura del sinus a la altura de la rodilla derecha, así como parte del hueco donde iba encajada la cabeza. Todo el lateral izquierdo, su parte inferior y posterior también están fracturadas. El lateral izquierdo presenta un rebaje a la altura del hombro para una refectio, al igual que la parte posterior donde existe un gran rebaje trabajado con cincel dentado y puntero para el encaje de otra pieza que correspondía a la zona de la espalda. Sus dimensiones máximas son: altura $1,40 \mathrm{~m}$; anchura $0,63 \mathrm{~m}$; antero-posterior $0,61 \mathrm{~m}$.

Sobre el umbo y el balteus de la estatua togada se aprecia parte de la túnica con varios plegados en «V» y ceñida por el balteus, por lo cual se forman unos pliegues sinuosos en el lateral derecho que caen sobre dicho balteus. El sinus se desarrolla hasta la rodilla derecha; su borde está limitado por pliegues anchos y profundos, mientras que su interior está constituido por un plegado casi paralelo y poco profundo que marca perfectamente la posición de la pierna derecha. El balteus está apoyado en la cadera derecha, desarrollándose en sentido diagonal y formado por pliegues profundos y anchos. El umbo, en forma de «V», ocupa una abundante superficie en la zona central del torso de la estatua, con pliegues de excelente factura, al igual que los del balteus. La ima toga queda ceñida a la pierna izquierda, separando con un profundo surco la tela que queda sobre la piel de la del resto que queda exenta. La cadera y el muslo izquierdo, muy marcados bajo el tejido, interrumpen la dirección diagonal de los pliegues del sinus, estando la superficie del tejido alisada y con pequeños pliegues casi verticales. La región dorsal está formada por pliegues oblicuos, apenas insinuados, que marcan ligeramente la forma de los glúteos y parte de los pliegues longitudinales.

La calidad se pone de manifiesto en la totalidad de la escultura y, en concreto, en la realización de 


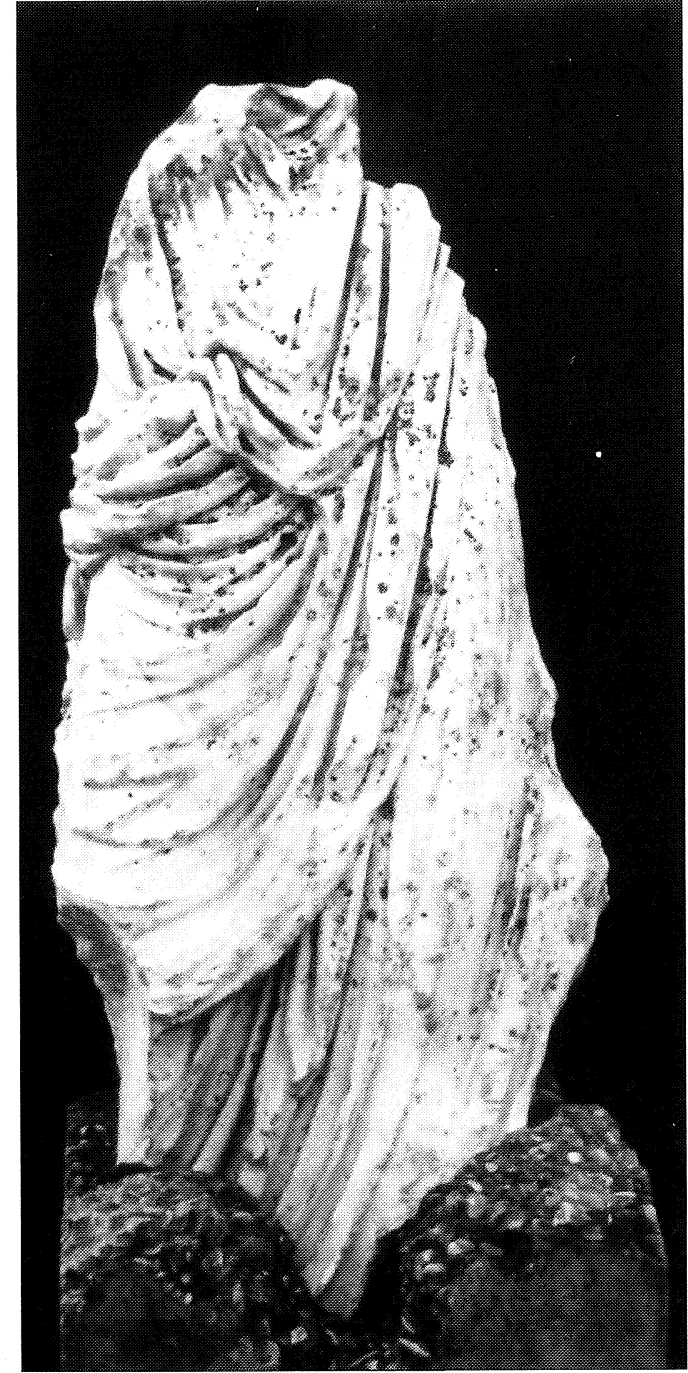

Figura 3.-Estatua togada $\mathrm{n}^{\circ}$ 2. Parte anterior. (Foto: A. Montejo).

partes como el balteus y el umbo y en detalles como los pliegues de la túnica que descansan sobre el balteus; en estas zonas los plegados se multiplican y se hace patente la torsión del tejido con un magistral uso del trépano. El resultado logrado es un rico contraste de luces y claroscuro en las distintas profundidades del paño.

\section{Estatua togada $n^{\circ} 3$ (fig. 5-6)}

Se conserva parte del torso y de las piernas, estando la escultura fracturada por encima del balteus a la altura del sinus en la pierna derecha y a lo largo de sus laterales. En la parte inferior se observa

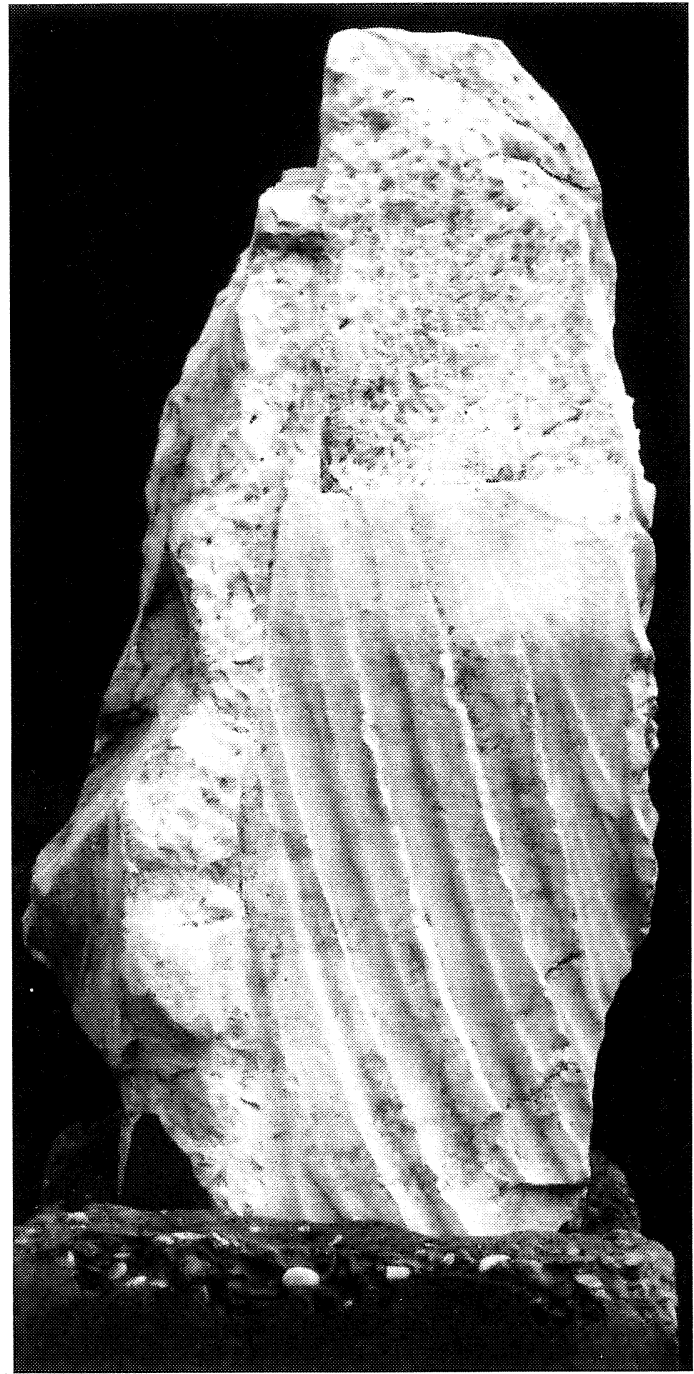

Figura 4.-Estatua togada $\mathrm{n}^{\circ} 2$. Parte posterior. (Foto: A. Montejo).

el arranque de la lacinia. Se aprecia parte de un perno de hierro y el correspondiente rebaje para la colocación del umbo. Sus dimensiones máximas son: altura 1,49 m; anchura 0,59 m; antero-posterior $0,41 \mathrm{~m}$.

En esta escultura togada podemos observar una pequeña parte del torso con varios de los pliegues oblicuos que configuran la túnica. En su lado derecho, el último pliegue ha sido concebido sinuosamente por el escultor, y con gran habilidad lo ha hecho caer sobre el balteus, indicando la movilidad de la túnica. Las distintas partes de la toga quedan definidas por profundos y marcados pliegues del tejido. El balteus está colocado sobre la cadera derecha, dispuesto en diagonal y formado por tres plie- 


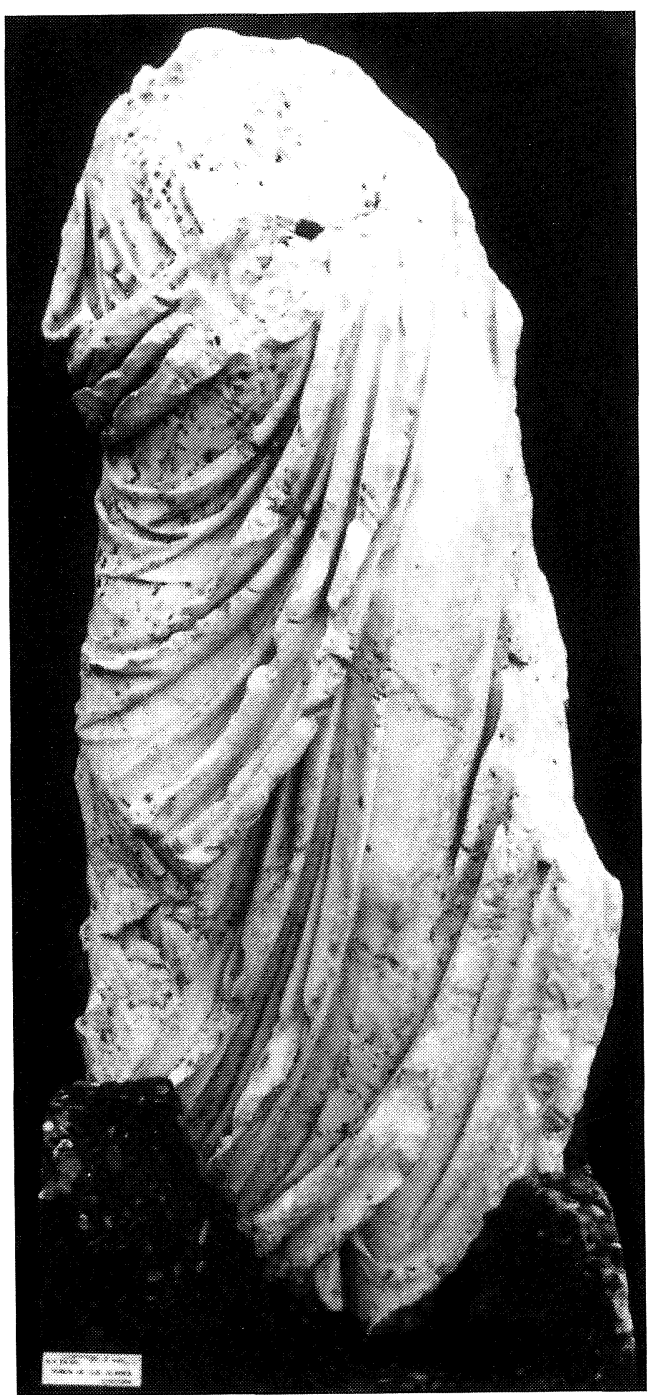

Figura 5.-Estatua togada $n^{\circ}$ 3. Parte anterior. (Foto: A. Montejo).

gues gruesos y claramente definidos. Encontramos paralelos para el balteus y la caída de la túnica de esta escultura en los togados del foro de Tarraco (Koppel, 1985, 16, Nr. 6, Taf. 6.1-6.2). El sinus está constituido por pliegues que se curvan y marcan, bajo el paño, la cadera y el muslo derecho; se halla limitado por varios plegados más profundos y gruesos. En el lateral izquierdo de la pieza, la ima toga, lisa y pegada a la superficie del cuerpo, transparenta la forma de la pierna derecha, frente a la parte inferior izquierda de la escultura donde el tejido se representa ricamente plegado. En la zona central, bajo la ima toga observamos los pliegues longitudinales que configuran la lacinia. La parte posterior del togado está formada por pliegues poco marca-

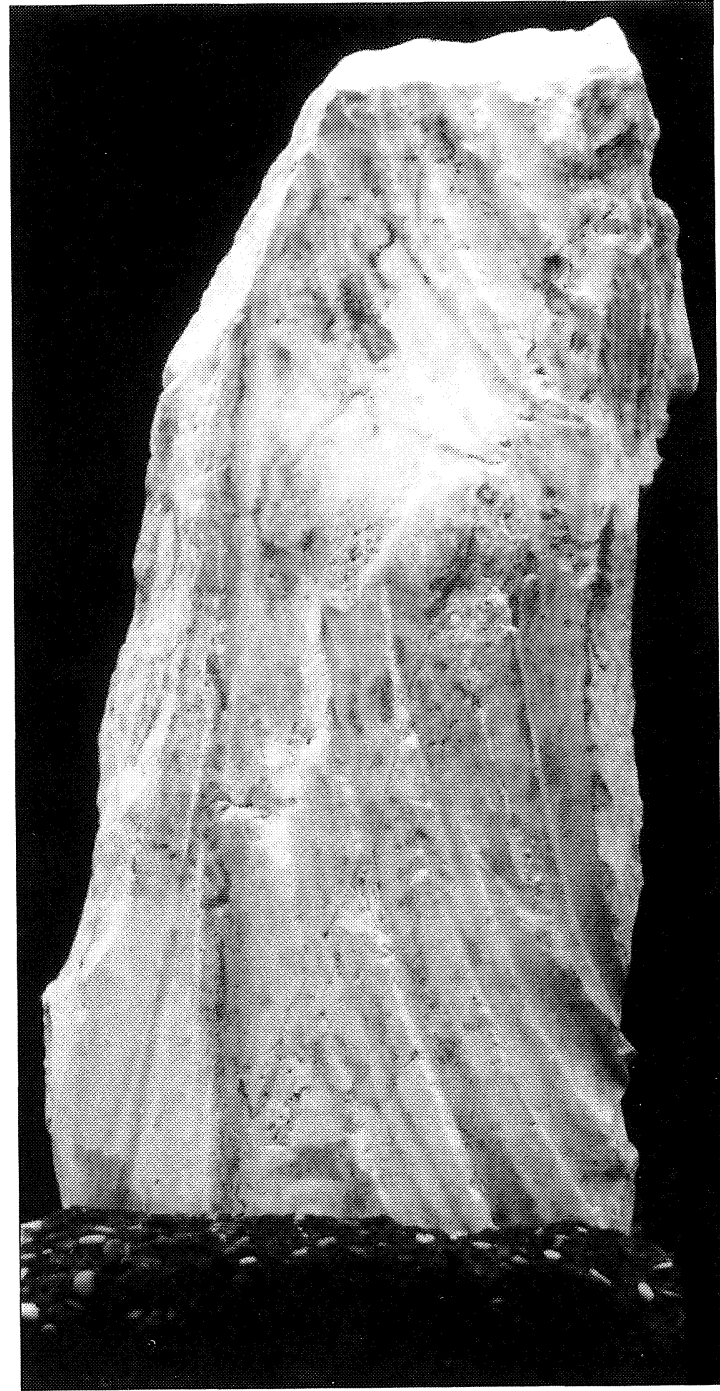

Figura 6.-Estatua togada $\mathrm{n}^{\circ} 3$. Parte posterior. (Foto: A. Montejo).

dos, diagonales y paralelos; sólo en su lateral izquierdo se conserva parte de dos pliegues longitudinales, individualizados mediante una incisión en la superficie del mármol.

Debemos resaltar en esta pieza cómo el escultor ha sabido interpretar a la perfección las formas del cuerpo, vistas a través de los pesados paños de la toga. Su interpretación ha sido plasmada tanto en la quietud de la cadera y pierna izquierda como en el movimiento de la flexión de la pierna derecha. La labor del trépano se realiza con gran delicadeza, sobre todo en ciertos detalles de la ejecución de los plegados; en concreto podemos resaltar el pliegue lateral de la túnica, mencionado anteriormente. 


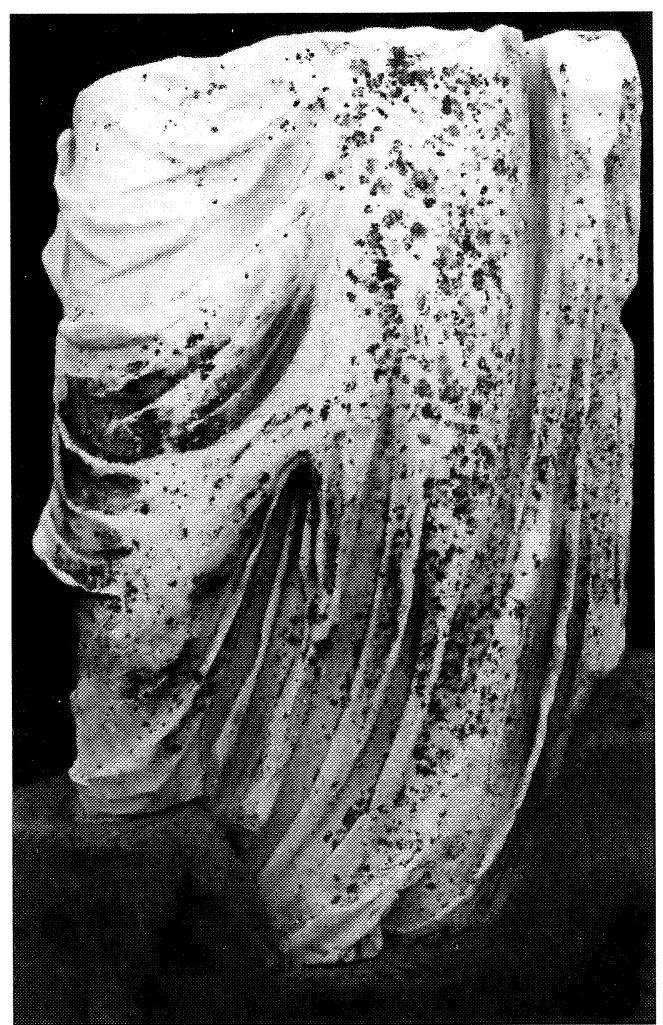

Figura 7.-Estatua togada $n^{\circ} 4$. Parte anterior. (Foto: A. Montejo).

Estatua togada $n^{\circ} 4$ (fig. 7-8)

Esta parte inferior del togado se encuentra fracturada intencionalmente a la altura de las caderas, en su parte superior, y en la zona de la pantorrillas, en su parte inferior. Las aristas de los pliegues del vestido y, en general, toda la superficie del mármol se encuentran muy deterioradas y afectadas por la acción de microorganismos, regularizando el acabado de esta escultura. En la espalda, en su parte inferior izquierda, se conserva un orificio rectangular trabajado con puntero para el encaje de otra pieza. Otro hueco rectangular de $0,13 \mathrm{~m}$ de profundidad se encuentra en su fractura superior; está trabajado con cincel dentado y su finalidad era encajar otra pieza correspondiente a la parte superior del togado. Sus dimensiones máximas son: altura $0,93 \mathrm{~m}$; anchura $0,62 \mathrm{~m}$; antero-posterior $0,33 \mathrm{~m}$.

En este fragmento observamos, aunque muy deteriorados, los pliegues del sinus que caen sobre la pierna derecha hasta la rodilla, con un plegado minucioso que se curva y rodea la figura. El borde del sinus y el espacio entre ambas piernas quedan marcados con un profundo pliegue. Sobre la pierna iz-

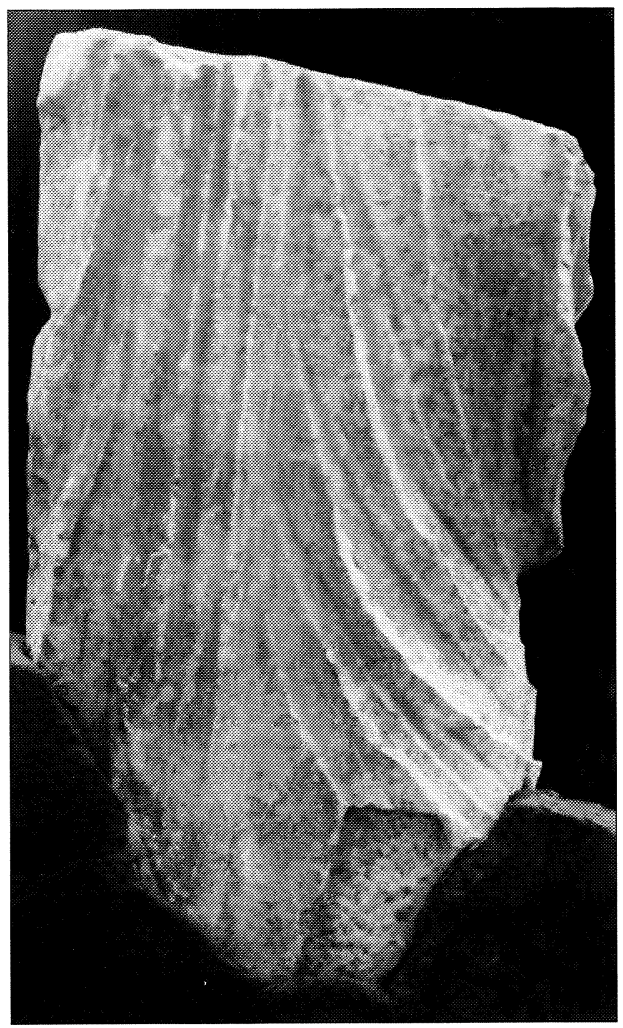

Figura 8.-Estatua togada $\mathrm{n}^{\circ}$ 4. Parte posterior. (Foto: A. Montejo).

quierda se desarrollan los pliegues de la ima toga, finos, paralelos y longitudinales, ligeramente oblicuos a partir de la rodilla, que permiten marcar la forma a través del tejido, a pesar de la erosión que ha regularizado la superficie. La línea exterior de la pierna izquierda queda también marcada por una profunda hendidura que transparenta la silueta del cuerpo y delimita la caída pesada de la toga, en rectos y gruesos pliegues, desde el brazo derecho, no conservado. En su zona dorsal se dispone un conjunto de pliegues oblicuos con gran profundidad que envuelven le cuerpo; en su parte izquierda se conservan cuatro pliegues longitudinales que pendían desde el hombro.

La magistral utilización de la labor de trépano queda plasmada en el efecto de claroscuro visible especialmente en el plegado situado entre ambas piernas, en el profundo pliegue situado a la derecha de la pierna izquierda y en el interior del sinus rodeando la pierna derecha. Un detalle reseñable de la calidad de la factura son los pequeños pliegues, labrados con gran sutileza y situados entre otros más pronunciados y profundos, que contribuyen al efecto de transparencia del muslo derecho bajo el sinus. 


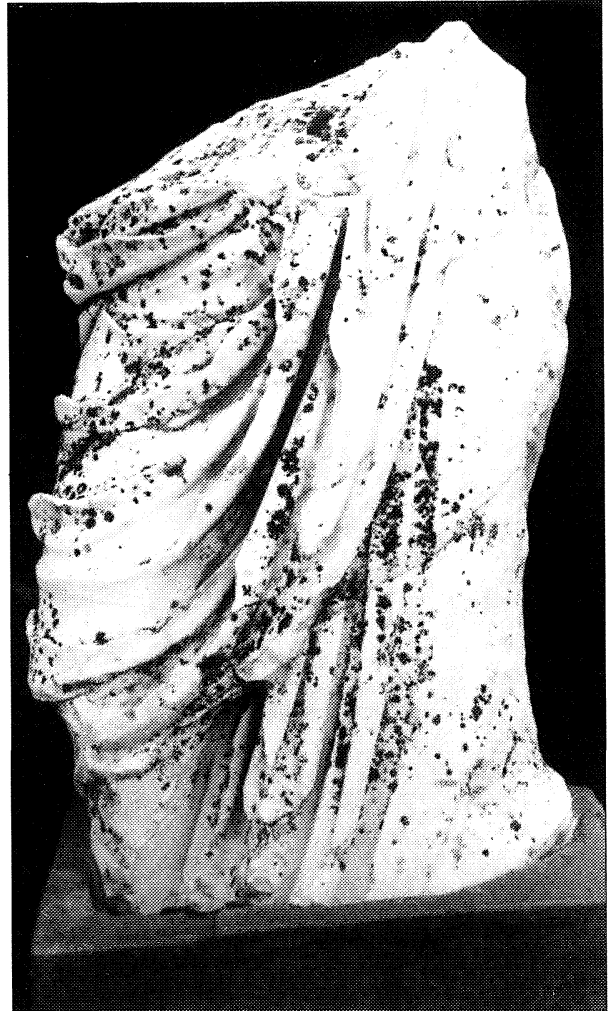

Figura 9.-Estatua togada $\mathrm{n}^{\circ}$ 5. Parte anterior. (Foto: A. Montejo).

\section{Estatua togada $n^{\circ} 5$ (fig. 9-10)}

El togado se halla fracturado de forma intencional en su parte superior a la altura de la cadera y, en la inferior, a la altura de las pantorrillas. El plegado se encuentra muy deteriorado y muchas de sus aristas están fracturadas. La superficie se halla muy erosionada y afectada por los microorganismos. En la parte posterior, en el espacio que ocuparían los pliegues longitudinales, la superficie del mármol se encuentra trabajada con un cincel dentado para el encaje de una pieza. Conserva un perno para el ensamblaje del umbo. Sus dimensiones máximas son: altura $0,93 \mathrm{~m}$; anchura $0,52 \mathrm{~m}$; antero-posterior $0,35 \mathrm{~m}$.

Esta escultura conserva parte de la toga, en concreto los pliegues del sinus que se desarrollan desde la cadera y caen sobre la pierna derecha hasta su rodilla, marcando la flexión de dicha pierna. El interior del sinus está formado por pliegues que se curvan y adaptan a la forma de la pierna, se caracterizan por unas aristas muy pronunciadas y definidas que indican los dobleces del tejido en esta zona. El límite del sinus se halla definido por una gran hendidura oblicua que comienza en la pierna iz-

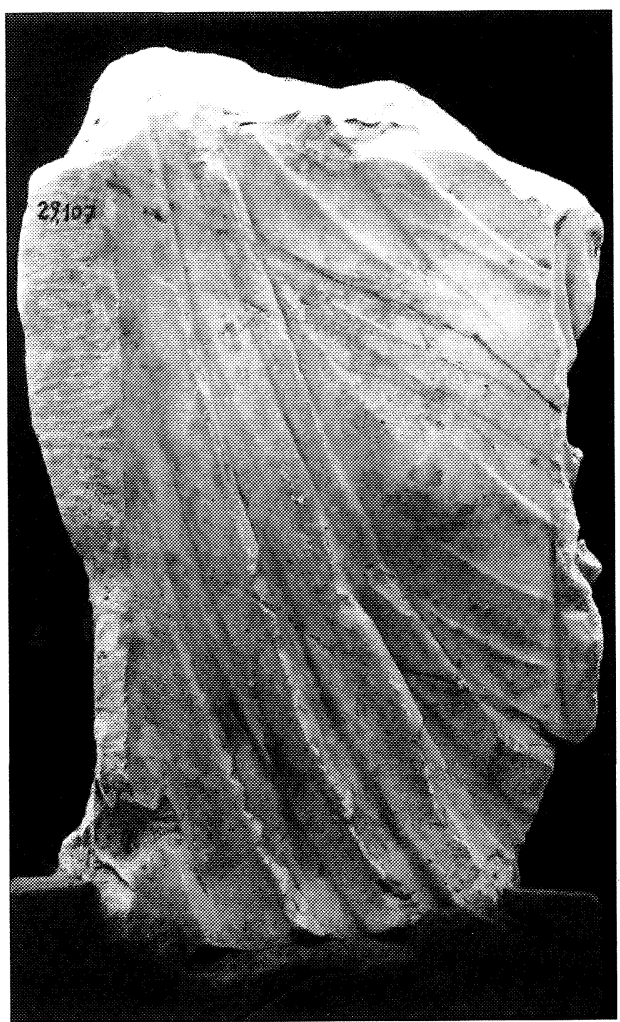

Figura 10.-Estatua togada $\mathrm{n}^{\circ}$ 5. Parte posterior (Foto: A. Montejo).

quierda y se desarrolla hacia la derecha, haciendo el artista en ella un verdadero alarde de la técnica del trépano. El borde del sinus está formado por varios pliegues anchos y oblicuos, fracturados sobre la rodilla derecha. Del balteus sólo se conserva parte de dos pliegues en su lateral derecho de características semejantes al resto de las estatuas de esta galería. La ima toga se ve en el espacio situado entre ambas piernas, constituida por plegados oblicuos y marcados y, en la pierna izquierda, por pliegues longitudinales, finos y rectos. En la parte posterior de la escultura el plegado, de gran plasticidad, se dispone en oblicuo y transparenta la forma redondeada de los glúteos.

\section{Estatua togada $n^{\circ} 6$ (fig. 11-12)}

Al igual que otros togados de esta serie, este fragmento se encuentra destrozado a la altura de la cadera y de las pantorrillas, conservándose parte del sinus y de la ima toga. Las fracturas presentan una superficie plana debido a su intencionalidad. En general, los pliegues se conservan muy mal, con nu- 


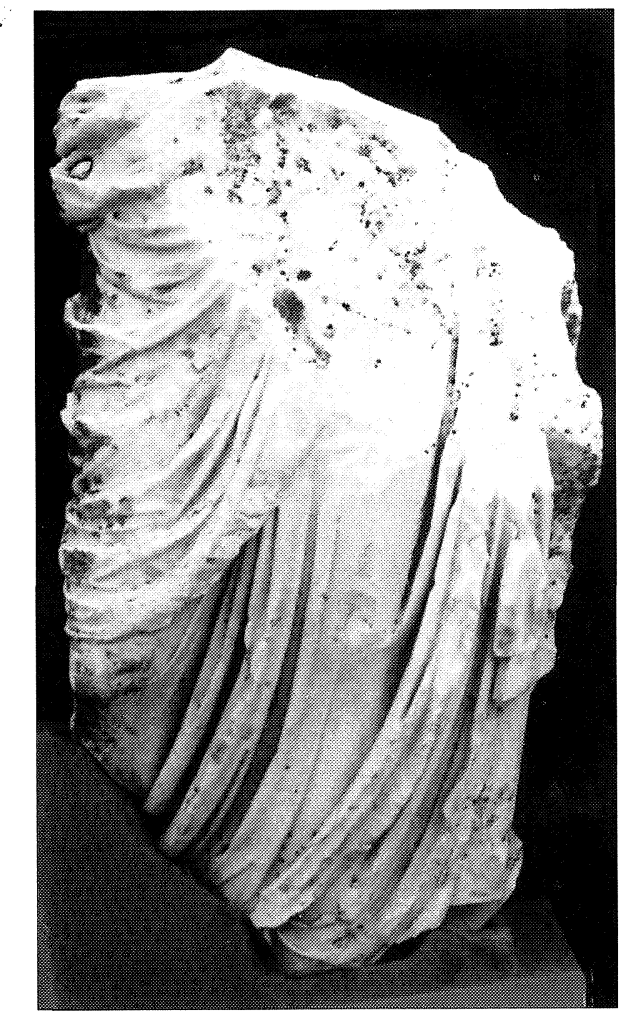

Figura 11.-Estatua togada $\mathrm{n}^{\circ}$ 6. Parte anterior. (Foto: A. Montejo)

merosas fracturas y afectados por microorganismos. En la parte dorsal, al final de los pliegues verticales que caían desde el hombro, se aprecia un hueco rectangular trabajado con puntero para el encaje de otra pieza que constituía la parte inferior de dichos pliegues. En el lateral izquierdo, entre los pliegues, se conserva un pequeño hueco rectangular para el ensamblaje de una pieza o bien, una refectio. Sus dimensiones máximas son: altura $1,15 \mathrm{~m}$; anchura 0,66 m; antero-posterior $0,38 \mathrm{~m}$.

Presenta muy deteriorados los pliegues del sinus que se desarrollan sobre la pierna derecha, por encima de la rodilla, se curvan y adaptan a la forma de la pierna, envolviendo la figura. La ima toga cae directamente sobre la pierna izquierda y, apenas $\sin$ pliegues, transparenta perfectamente su forma. A derecha e izquierda de esta pierna se multiplican los pliegues de la toga, que se disponen longitudinales y profundos, para luego curvarse bajo la rodilla. En la parte izquierda de la escultura la abundancia del plegado indica el volumen de tejido que recogía el brazo izquierdo para luego, desde él, caer pesadamente. En este lateral izquierdo los pliegues profundos se disponen casi paralelos en forma de $« \mathrm{~V} »$.

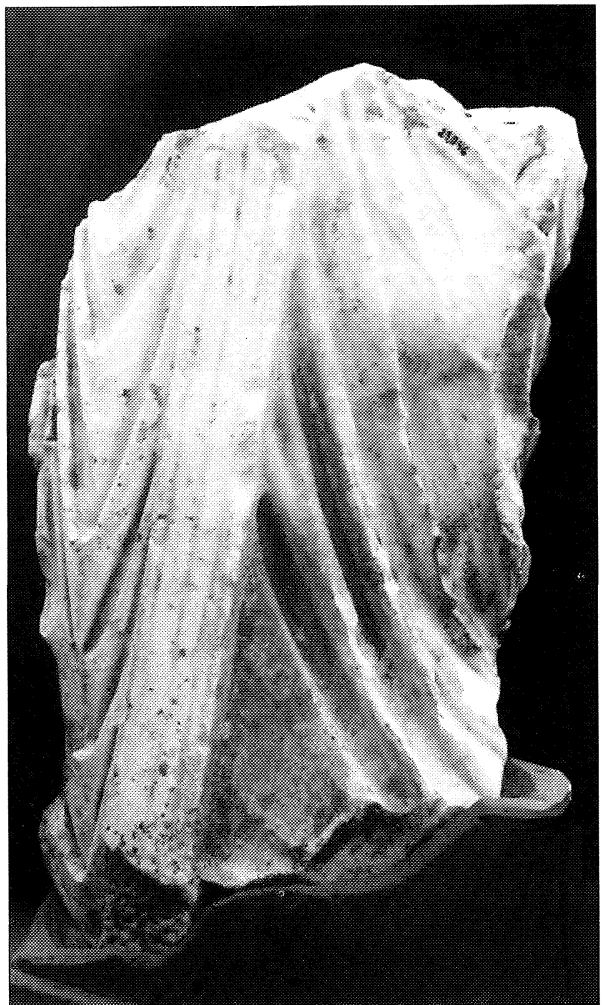

Figura 12.-Estatua togada $\mathrm{n}^{\circ}$ 6. Parte posterior. (Foto: A. Montejo).

Sobre la cadera se desarrolla el balteus, del que sólo se conserva una pequeña parte de tres gruesos pliegues separados por profundas hendiduras, junto a otros pequeños dobleces. En la parte dorsal de la escultura los pliegues están realizados con profundidad y dispuestos en diagonal junto a los cuatro pliegues longitudinales que penden del hombro izquierdo, sólo insinuados.

\section{Estatua togada $n^{\circ} 7$ (fig. 13-14)}

Esta pieza está fracturada intencionadamente por encima del balteus, conservando parte del torso y su parte inferior desde la zona media de las piernas. Los pliegues del lateral izquierdo están fracturados y el umbo no se conserva. Las aristas de los pliegues están muy deterioradas. Se aprecian las huellas del trépano entre los pliegues de balteus. Sus dimensiones máximas son altura $0,9 \mathrm{~m}$; anchura 0,7 $\mathrm{m}$; antero-posterior $0,37 \mathrm{~m}$.

Presenta en el torso dos pliegues, profundos y oblicuos, que indican la presión del balteus sobre el tejido de la túnica, adquiriendo uno de estos 


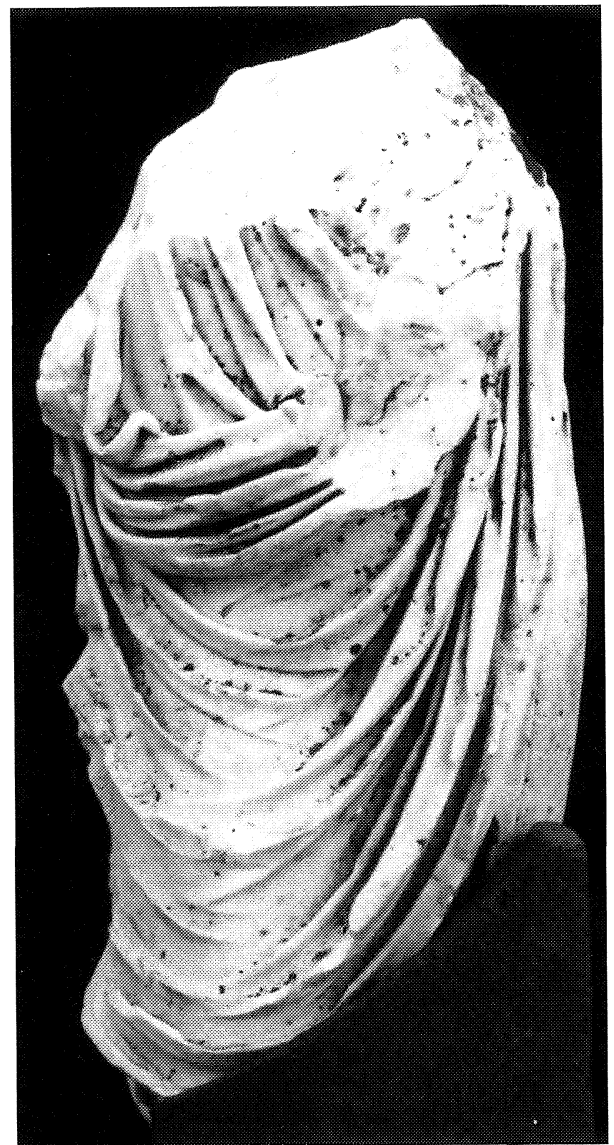

Figura 13.-Estatua togada $n^{\circ}$ 7. Parte anterior (Foto: A. Montejo).

pliegues una forma sinuosa al descansar sobre la toga, de manera semejante a las estatuas $n^{\text {os }} 1,2$ y 3. El resto de los pliegues de la túnica, planos y anchos, muestran la simplicación de la labra. Por su parte, la toga se ajusta a la cadera izquierda con un balteus formado por tres gruesos pliegues casi paralelos, marcados de manera profunda y con unos dobleces en su zona intermedia. El sinus se desarrolla en grandes y profundos pliegues con aristas vueltas y dispuestos espaciadamente, que se curvan sobre la pierna derecha, marcando la forma de ésta. También se conservan varios pliegues longitudinales y paralelos, situados entre ambas piernas que corresponden a la ima toga. El tejido que cae sobre la pierna izquierda, apenas sin plegado, se adhiere y transparenta su forma. En la parte posterior de la escultura destacamos la profundidad y calidad de los pliegues de la ima toga que, tras rodear la pantorrilla derecha, ascienden por la espalda. Otros pliegues de la espalda se desarrollan en oblicuo y corresponden al movimiento que se pro-

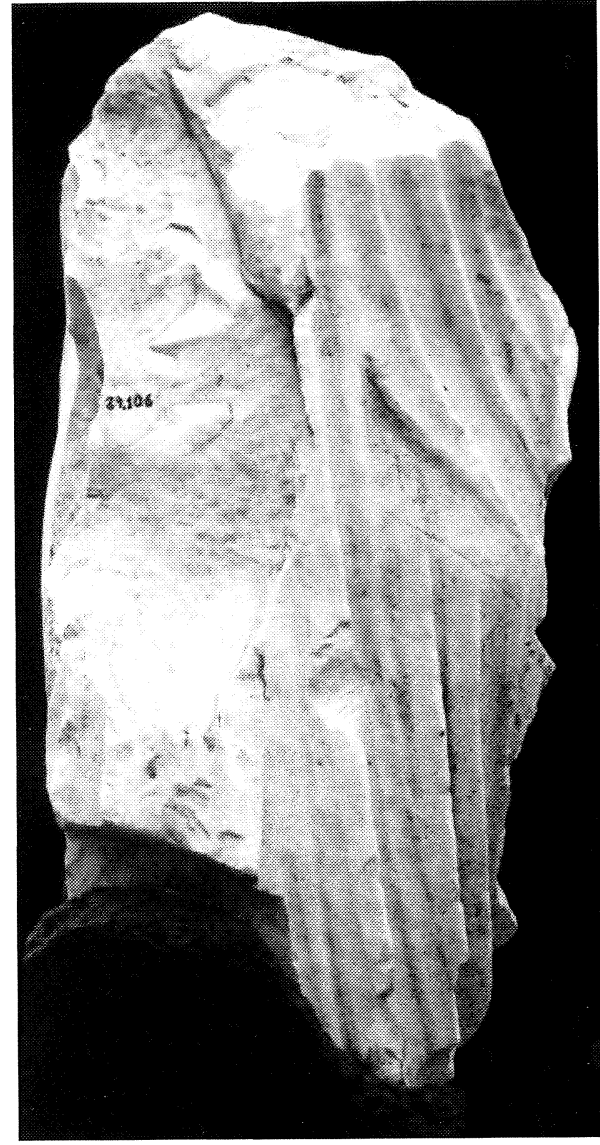

Figura 14.-Estatua togada $\mathrm{n}^{\circ}$ 7. Parte posterior (Foto: A. Montejo).

duce en la toga al flexionar el brazo derecho. Toda la mitad izquierda se halla fracturada, aunque en su zona inferior se conserva parte del volumen sobresaliente de los pliegues verticales que penden desde el hombro. Su factura permite marcar ligeramente la forma de los glúteos.

\section{Estatua togada $n^{\circ} 8$ (fig. 15-16)}

Fragmento correspondiente a la parte inferior de un togado que conserva la zona de las piernas con la caída de los pliegues del sinus y de la ima toga. La pieza está fracturada en la parte alta de los muslos y bajo las rodillas, llegando hasta el tobillo en la pierna izquierda. Las aristas de los pliegues presentan múltiples roturas y la superficie del mármol está cubierta de microorganismos. En la región dorsal se aprecia cómo el lugar ocupado por los pliegues verticales se halla alisado y cubierto por multitud de pequeños agujeritos y en su parte inferior se apre- 


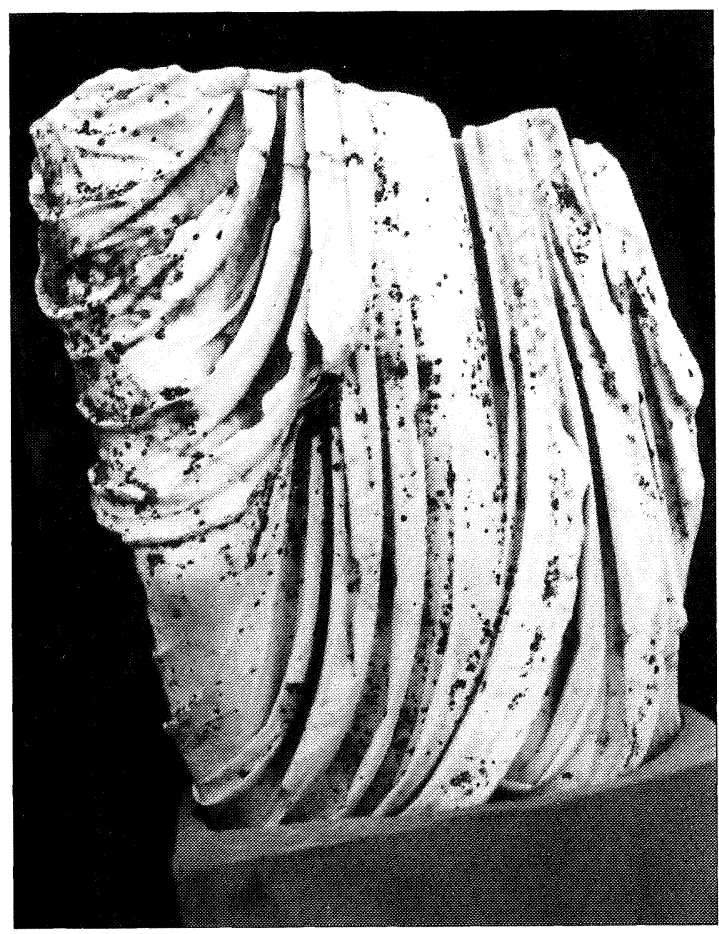

Figura 15.-Estatua togada $n^{\circ} 8$. Parte anterior. (Foto: A. Montejo).

cia un perno cuya funcionalidad era facilitar el acople de otra pieza escultórica. Se conservan huellas del cincel en su parte posterior. Sus dimensiones máximas son: altura $0,97 \mathrm{~m}$; anchura $0,79 \mathrm{~m}$; antero-posterior $0,34 \mathrm{~m}$.

Sobre la pierna derecha, hasta la rodilla, se desarrolla el sinus de este togado, formado por pliegues curvos, casi paralelos y realizados con gran profundidad. En la pierna izquierda la ima toga se adhiere con pliegues muy finos que marcan su forma. A la izquierda de la escultura se desarrolla un amplio volumen de tejido que se configura en multitud de plegados longitudinales, que caían pesadamente desde el brazo, no conservado, y que se van curvando a la vez que envuelven la figura. Bajo el sinus y entre ambas piernas también se extiende la ima toga, bajo la cual se aprecia el arranque de los tres pliegues de la lacinia. La parte dorsal se encuentra bien labrada, aunque los pliegues se hallan insinuados.

El escultor utiliza con gran maestría la labor de trépano consiguiendo contrastes de claroscuro en el tratamiento de los pliegues, especialmente en los plegados interiores del sinus y el gran volumen de tejido que se sitúa a la izquierda de la escultura.

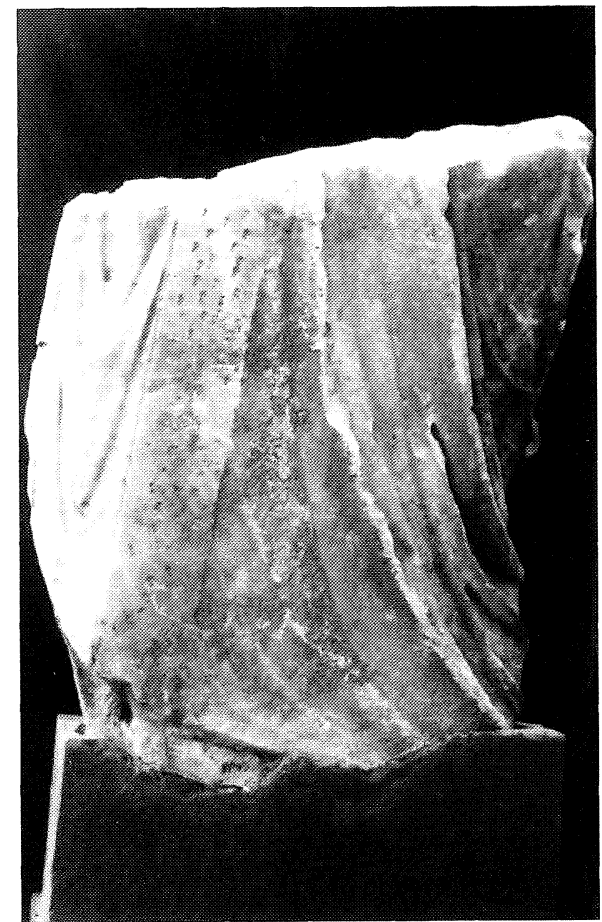

Figura 16.-Estatua togada $n^{\circ} 8$. Parte posterior. (Foto: A. Montejo).

\section{Estatua togada $n^{\circ} 9$ (fig. 17-18)}

Se conserva la pierna izquierda de este togado desde el muslo hasta la rodilla y el conjunto de pliegues longitudinales situados a la izquierda de dicha pierna. El sinus está prácticamente perdido, salvo el inicio de los pliegues anexos a la pierna derecha, que sí se conservan. Las aristas de los pliegues están muy erosionadas y fracturadas. En la parte superior de la escultura se halla un perno metálico para engarzar otra pieza que corresponde al brazo izquierdo, flexionado y extendido hacia adelante. Sus dimensiones máximas son: altura $1,17 \mathrm{~m}$; anchura $0,51 \mathrm{~m}$; antero-posterior $0,39 \mathrm{~m}$.

La ima toga se aprecia sobre la pierna izquierda, a la que se adhiere con una superficie casi lisa que transparenta perfectamente la forma de la pierna y de la cadera. A la derecha, con una ligera curva en la parte inferior, se conserva parte de los pliegues que constituyen el sinus de la toga. En la parte izquierda de la escultura se observa un conjunto de pliegues gruesos y longitudinales que caería pesadamente desde el brazo izquierdo, desaparecido. En la parte de transición entre el lateral izquierdo y la espalda se desarrollan unos pliegues profundos y casi paralelos con forma de «V», producto del recogido 


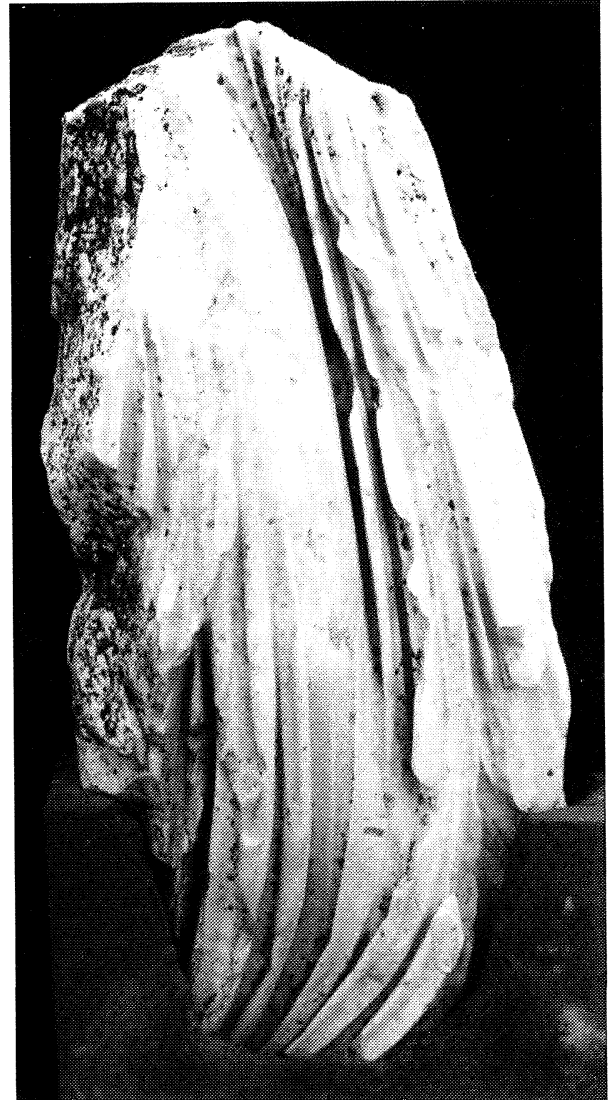

Figura 17.-Estatua togada $n^{\circ}$ 9. Parte anterior. (Foto: A. Montejo).

de la toga sobre el brazo izquierdo. La zona dorsal presenta unos plegados en diagonal con gran profundidad y tres pliegues longitudinales que se desarrollan a lo largo de toda su parte izquierda.

Los pliegues de la toga de la pierna izquierda éstos caen verticalmente y son finos y de escasa profundidad, dando lugar a un efecto de transparencia. A la izquierda de la pierna se desarrollan unos pliegues curvilíneos de factura profunda. El inicio del sinus queda configurado por pliegues de una hendidura considerable.

\section{Estatua togada $n^{\circ} 10$ (fig. 19-20)}

Se conserva el torso del togado, aunque le falta todo el lateral izquierdo con una fractura intencionada en diagonal y paralela a los pliegues del umbo y del sinus. En la parte superior del fragmento se observan tres fracturas casi rectas, que han hecho que se pierdan los dos hombros y el cuello. También se han conservado los pliegues del sinus que caen

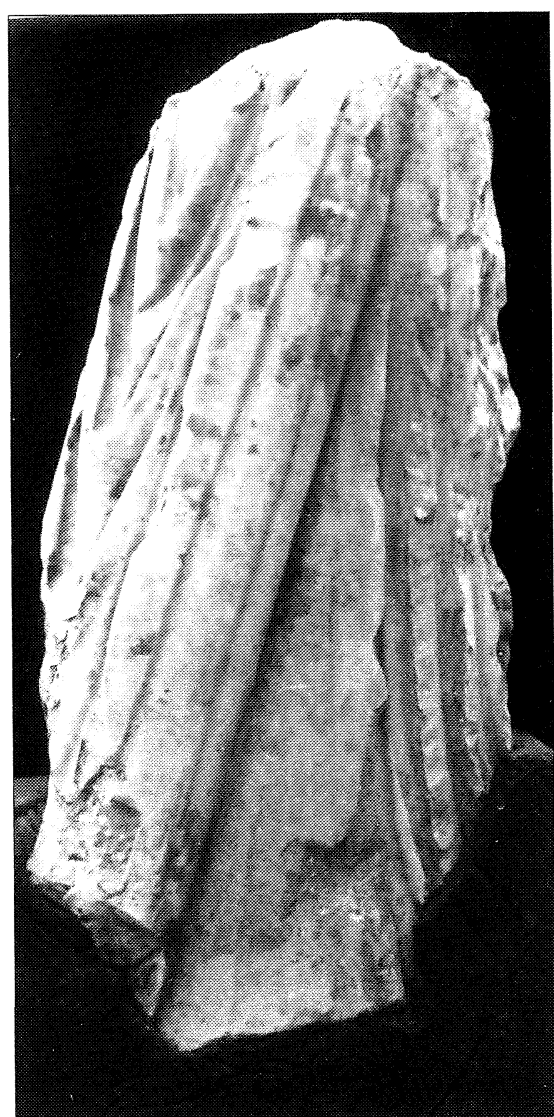

Figura 18.-Estatua togada $n^{\circ}$ 9. Parte posterior. (Foto: A. Montejo).

sobre el muslo derecho. Las aristas de los pliegues del umbo se encuentran muy deterioradas. La superficie del mármol está afectada de microorganismos. En el hombro derecho se conserva un perno para engarzar una pieza distinta. En el antebrazo derecho aparecen también dos pernos para encajar el brazo. En la parte dorsal, localizado en el centro, se observa un hueco rectangular cuya funcionalidad está relacionada con el encaje de otra pieza. Sus dimensiones máximas son: altura $0,92 \mathrm{~m}$; anchura $0,60 \mathrm{~m}$; antero-posterior $0,45 \mathrm{~m}$.

De este togado nos ha llegado la parte superior, cubierta por un conjunto de pliegues dispuestos en distintas direcciones, muy marcados y que realzan el efecto de claroscuro. Sobre el pecho se dispone la túnica en cinco anchos pliegues en forma de $« \mathrm{~V} »$, dotados de gran relieve y que contribuyen a crear un rico contraste de luces; estos pliegues parten del hombro derecho y quedan cubiertos, en su parte izquierda, por los pliegues del umbo. La túnica queda completamente adherida al torso mediante unos pliegues más superficiales que modelan el pecho y 


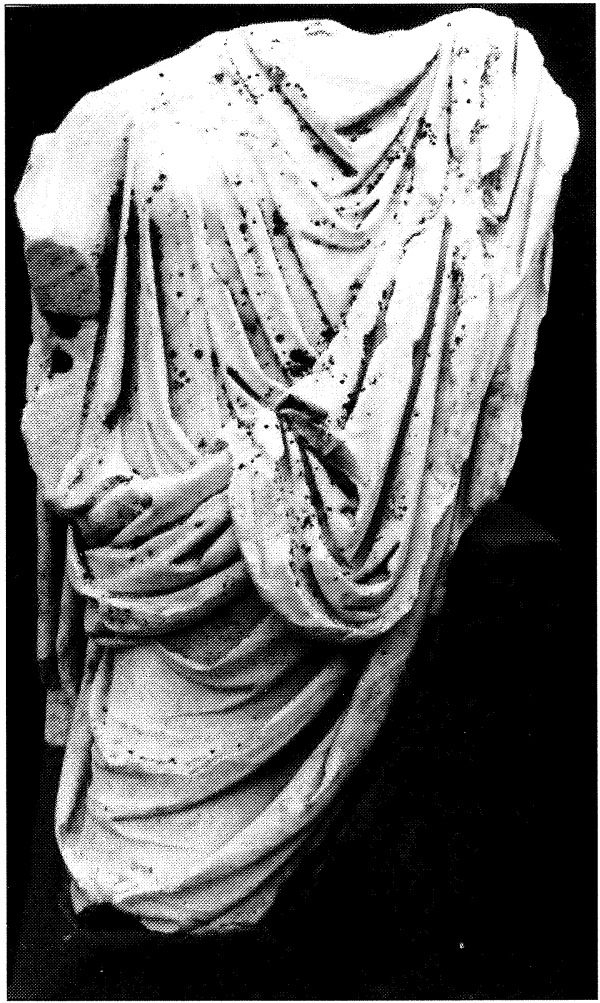

Figura 19.-Estatua togada $\mathrm{n}^{\circ} 10$. Parte anterior. (Foto: A. Montejo)

el hombro. Al igual que otros togados de esta serie - las estatuas $n^{\circ \mathrm{s}} 1,2,3$ y 7 -, esta escultura presenta la caída de un pliegue de la túnica sobre el balteus en su lateral derecho. En la cadera y pierna derecha se conservan los primeros pliegues del interior del sinus, finos y poco marcados, que quedan adheridos a la pierna resaltando su forma. También se aprecia parte del sinus en el lateral derecho, tras el brazo, constituido por pliegues anchos y profundos que provienen de la curva que realiza el sinus sobre la pierna y luego ascienden rectos hacia el hombro. El umbo, cuyos pliegues irregulares presentan una clara forma en «U»y aristas marcadas, transmite el peso del tejido. El balteus se halla constituido por tres pliegues anchos, con varios entrantes y salientes, que se apoyan en la cintura marcando una curva. En la región dorsal los pliegues de la toga están esbozados ligeramente en el lateral derecho, con una trayectoria oblicua. Los pliegues que pasan por el hombro izquierdo, procedentes del sinus, penden en una masa compacta de tres o cuatro plegados incisos, según la altura, configurando un listón rectagular y alargado, carente de plasticidad; a pesar de estar trabajados de una manera más somera, revelan gran cuidado y gran calidad.

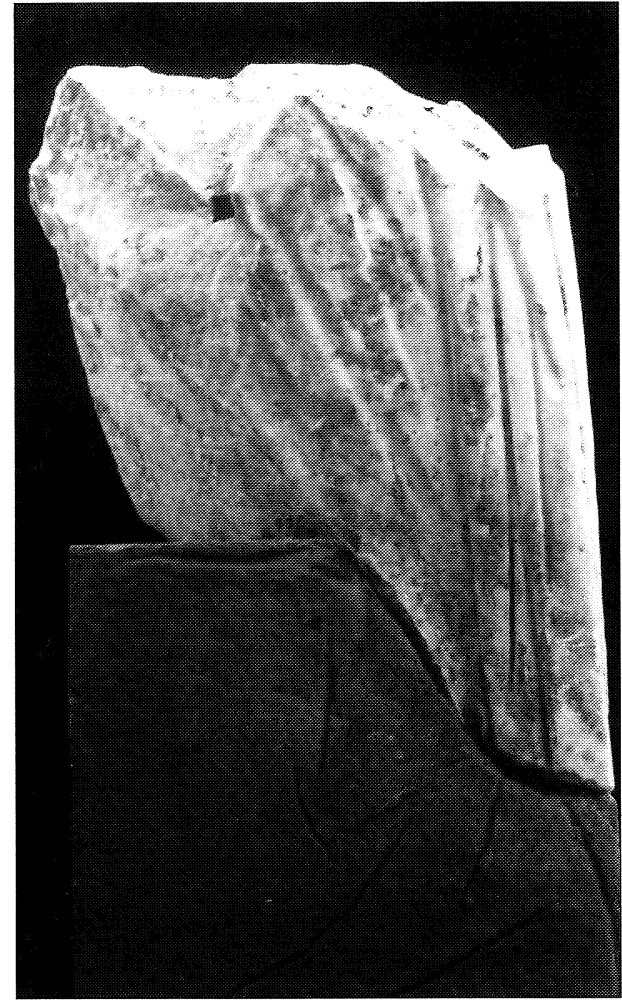

Figura 20.-Estatua togada $\mathrm{n}^{\circ} 10$. Parte posterior. (Foto: A. Montejo).

El umbo está realizado con pliegues claramente diferenciados, que transmiten la pesadez del tejido y describen una curva alargada sobre y por debajo del balteus para luego ascender por el torso, son muy similares a dos ejemplares del Museo Arqueológico Provincial de Cádiz, procedentes de Asido (García y Bellido, 1949, 190, nº 220-221, lám. 160), fechados por Goette (1990, 124, Ba227-228) en época claudia. Por otra parte, la elaboración del balteus en tres gruesos pliegues con sus tres dobleces intermedios y con la caída curva en su parte superior de un pliegue de la túnica es comparable a los togados claudios de Tarraco (Goette, 1990, 124, Ba238, Taf. 10.3).

\section{Estatua togada $n^{\circ} 11$ (fig. 21-22)}

Se conserva la parte inferior del togado, en su lateral derecho desde la mitad del muslo hasta la rodilla y en su lateral izquierdo desde la cadera hasta la lacinia. Las fracturas, superior e inferior, presentan una superficie en diagonal que delatan su intencionalidad. Las aristas de los pliegues del sinus están muy deterioradas y fracturadas. Toda la super- 


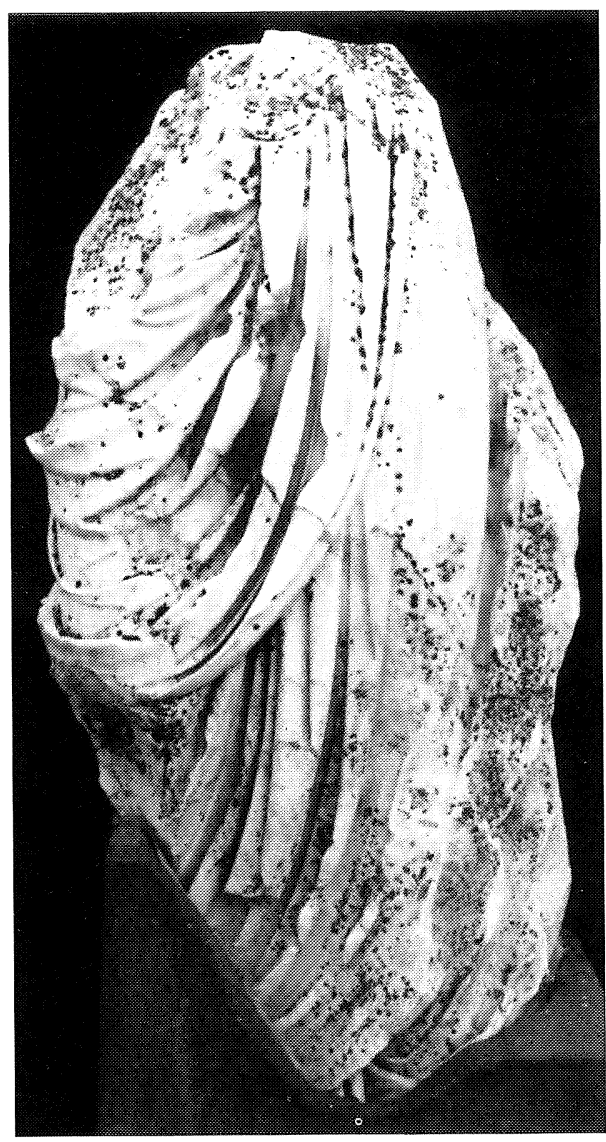

Figura 21.-Estatua togada $\mathrm{n}^{\circ} 11$. Parte anterior. (Foto: A. Montejo).

ficie del mármol ha sido cubierta por microorganismos. Su parte posterior presenta abundantes huellas de cincel y puntero. No se han diferenciado los pliegues de la toga que penden del hombro izquierdo en vertical y en la parte superior la superficie ha sido trabajada con puntero para el encaje de otra pieza escultórica. Sus dimensiones máximas son: altura $1,28 \mathrm{~m}$; anchura $0,60 \mathrm{~m}$; antero-posterior $0,38 \mathrm{~m}$.

En este fragmento de togado se aprecia la parte del sinus que cae sobre la pierna derecha, la ima toga que se desarrolla sobre la pierna izquierda y entre ambas piernas partiendo bajo el sinus, y el arranque de los tres pliegues longitudinales de la lacinia. El amplio sinus está formado por una extensa masa de pliegues anchos y profundos que dan lugar a un logrado efecto de claroscuro y pasan por encima de la pierna, dibujando una curva que asciende por el lateral derecho y ciñen el tejido a la pierna. El interior del sinus se adhiere al muslo y rodilla derecha, estando en este lugar estructurado en pliegues finos y curvilíneos con agudas aristas y dispuestos en forma concéntrica. En la zona poste-

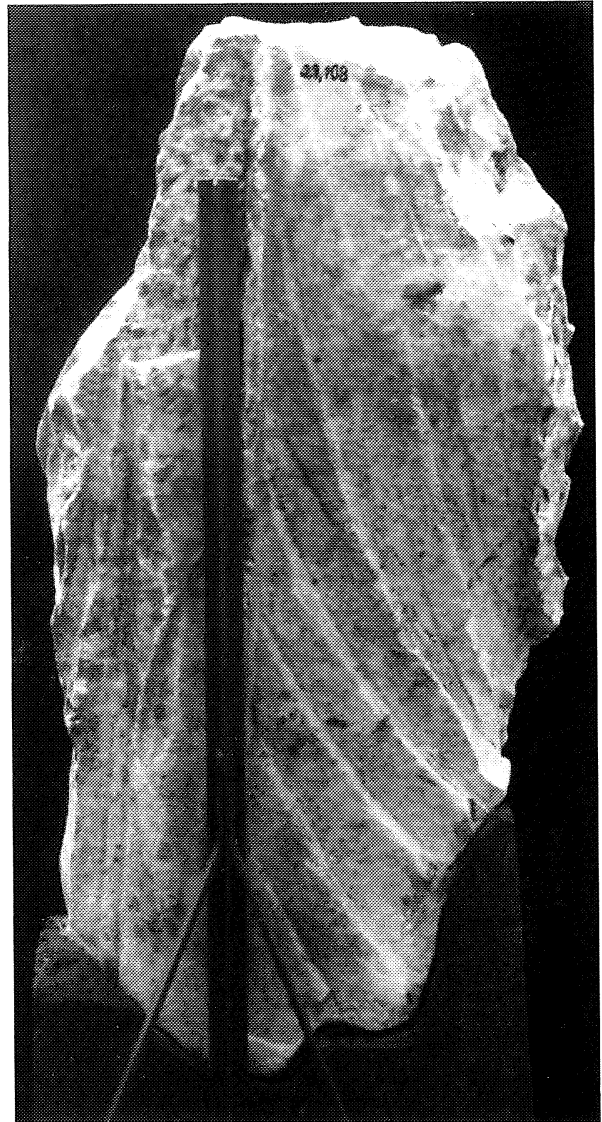

Figura 22.-Estatua togada $n^{\circ} 11$. Parte posterior (Foto: A. Montejo)

rior el plegado de la toga se desarrolla en diagonal con pliegues de escasa profundidad, sólo insinuados. La terminación inacabada de esta parte puede indicarnos que la escultura no era vista por el espectador y también la calidad de su escultor.

\section{ESTUDIO TIPOLÓGICO}

Siguiendo con la ordenación establecida por Goette (1990) la presente serie de esculturas corresponde al amplio tipo «Ba», «togados con umbo en forma de 'U' del siglo I d.C.»y, en concreto, al grupo claudio (Goette, 1990, 35-37). En este momento se realizan galerías de estatuas, colocadas la mayoría de las veces en los espacios públicos de las ciudades. Estas representaciones de togados pueden ser fechadas gracias a su estudio comparativo con los retratos de la familia imperial.

A excepción de las obras orientales, en todo el Imperio se desarrolla una gran uniformidad tipológica y estilística para las estatuas togadas de época 
claudia, que también se prolonga en los años siguientes. Esta uniformidad llega a ser realmente monótona si se tiene presente la gran masa de togados de este periodo. A partir de época flavia se observará un retroceso en el número de togados, de modo que la representación cívica con toga tiene a finales de época julioclaudia su punto cuantitativo más alto (Goette, 1990, 37). De hecho, el volumen mayor de togados cordobeses también se sitúa tipológica y cronológicamente en esta época claudia (López, 1997, 217).

En relación a la forma de llevar la toga y a los motivos del plegado, las piezas incluidas por Goette en el extenso grupo de togados de época claudia se distinguen por un umbo en forma de «U» que reduce su tamaño, en contraposición con la amplitud y el volumen de las formas augústeas. El sinus se desarrolla sobre la pierna derecha, extendiéndose hasta la rodilla y dejando transparentar la forma de la pierna a través de sus pliegues interiores, realizados con estrechas aristas vueltas hacia arriba. La ima toga comienza a resaltar la forma de la pierna izquierda, ya que sobre ésta el escultor trabaja el tejido de la toga con un escaso plegado, casi liso, lo que permite su adherencia a la piel.

Por lo que respecta a la galería de esculturas de la Avda. Ronda de Tejares de Córdoba, su gran similitud tipológica y estilística nos permite abordarlas de manera global. En cuanto a las diferentes partes de la toga ${ }^{8}$, nos referimos primeramente al umbo, que se ha conservado sólo en tres esculturas, las $\mathrm{n}^{\text {os }} 1,2$ y 10 . Presenta una forma amplia con pliegues anchos e irregulares que penden sobre el balteus y trasmiten con su factura el peso del tejido. Los pliegues del úmbo ocupan una amplia superficie en la zona central de la cintura de estas estatuas. Su forma casi semicircular permite encuadrar estas esculturas en el tipo genérico que Goette (1990, 29-42) define como umbo tipo «Ba» con forma de «U», propio del siglo I d.C. Debemos diferenciar el togado $n^{\circ} 2$, cuyos pliegues presentan un perfil más anguloso y la forma semicircular se transforma en una forma más cerrada, más en « $\mathrm{V} »$.

El balteus, cuyo trazado atraviesa diagonalmente la composición, se conserva en las estatuas $n^{\text {os }} 2$, $3,6,7$ y 10 . Se apoya en la cadera izquierda y está formado por tres pliegues, casi paralelos, profundos y anchos, claramente definidos, que presentan también el detalle de unos dobleces en su zona intermedia —estatuas $n^{\circ *} 7$ y 10 -

${ }^{8}$ En el apartado anterior dedicado a la conservación y descripción de las piezas hemos mencionado paralelos tipológicos concretos para algunas de estas esculturas.
El sinus está formado por un conjunto de pliegues curvos y paralelos que se adaptan perfectamente a la forma de la pierna derecha, la envuelven y ascienden por la espalda. Los pliegues del interior, claramente definidos e individualizados, presentan unas aristas vueltas en su parte superior, muy marcadas y angulosas en los togados $\mathrm{n}^{\mathrm{os}} 5,8,10$ y 11 , siendo más suaves en los togados $\mathrm{n}^{\circ \mathrm{s}} 1,2,3$ y 7 . El plegado que delimita la parte exterior del sinus se desarrolla desde la cintura y describe con un haz de pliegues la caída pesada del tejido; presenta también unas aristas más suaves que en su interior. Su desarrollo se extiende hasta la rodilla, llegando por encima de ésta en las estatuas $\mathrm{n}^{\text {os }} 1,4,5,6$ y 8 , y cubriéndola en la estatua $n^{\circ} 11$. Este tipo de sinus lo hallamos en algunos de los togados clasificados por Goette, como los del «Foro de Mármol» de Mérida (1990, 128, Ba303-306a) situados tipológicamente entre las épocas de Claudio y de Nerón.

El tratamiento de parte de la ima toga en estatuas como las $\mathrm{n}^{\text {os }} 2,3,6$ y 9 hace que la toga se adhiera a la superfice del cuerpo y transparente casi totalmente la pierna izquierda, desde la cadera en algunos casos. Este interés por representar la toga muy pegada al cuerpo con pliegues agudos y profundos será un elemento característico de los togados del siguiente grupo establecido por Goette, de finales de época claudia y principios de época neroniana (Goette, 1990, 37-40).

El conjunto de personajes togados presenta importantes similitudes tipológicas con togados de la península ibérica como los de Tarraco (Goette, 1990, 124, Ba236, Ba238, Taf. 10.2-3), Baelo Claudia (Goette, 1990, 124, Ba234) y Asido (Goette, 1990, 124, Ba227-229). Fuera de la Península destacamos como paralelos tipológicos los togados del teatro de Leptis Magna y los del teatro de Caere (Goette, 1990, 122-124, Ba186-187, Ba240-243).

Las características que definen tipológicamente la toga y los datos cronológicos aportados por los paralelos mencionados anteriormente nos permiten adscribir esta serie de togados a plena época claudia.

\section{EL TALLER}

En época claudia se produce, tanto en la capital como en la provincia cordobesa, una auténtica eclosión en la producción de obras, que sobresalen con creces no sólo por su número sino por su calidad. Nos encontramos en un momento de madurez de los talleres escultóricos, conocedores extraordinarios de los patrones metropolitanos, donde el eclecticismo y 
la creatividad se alzan en este periodo alcanzando altas cotas de calidad; sirva como ejemplo contemporáneo a los togados de este taller una escultura femenina sedente del entorno del foro colonial de la ciudad (López, 1997, 147-148, nº cat. 52, lám. LIII, A-C). Es también en este momento cuando, a raíz de la intensa labor edilicia que se realiza en la ciudad, se producen los primeros capiteles por parte de los talleres locales (Márquez, 1991, 123), coincidiendo con la construcción del templo romano de la calle Claudio Marcelo.

Encontramos en las once esculturas togadas de este taller un tratamiento del plegado caracterizado por una elaboración excelente, siendo los pliegues profundos y definidos por gruesas aristas vueltas. En cambio, la parte posterior de las piezas, aunque el acabado es en general cuidado y se transmiten los volúmenes de los glúteos, está superficialmente trabajada. Por otra parte, en el plegado de la túnica, ancho y espaciado, se simplifica la labra.

Destaca el minucioso trabajo del artista en los conseguidos contrastes de luz y de profundidad del tejido; mediante su labor de trépano en la realización de los pliegues de la túnica y de la toga logra un marcado efecto de claroscuro en los paños.

El escultor ha sabido modelar con toda corrección las formas del cuerpo vistas a través de la pesada y amplia toga. Esta interpretación ha sido plasmada tanto en la quietud de la cadera y pierna izquierda como en la flexión de la pierna derecha. La ima toga queda adherida totalmente a la cadera y a la pierna izquierda, recta y erguida, con pequeños y finos pliegues de escaso relieve que se disponen de manera espaciada y casi verticales sobre dicha pierna, cuya silueta está resaltada mediante un profundo pliegue situado a su izquierda. Un conjunto de pliegues casi paralelos que se curvan forman el sinus, que se adapta perfectamente a la superficie de la pierna derecha tanto en la parte anterior como en el lateral derecho.

Aquellos togados que han conservado parte del torso, como son $\operatorname{los} \mathrm{n}^{\mathrm{os}} 1,2,3,7$ y 10 , presentan un motivo común en el plegado de la túnica. Uno o varios de los pliegues del costado son representados sinuosamente cayendo sobre el balteus. Esta característica, que podemos ampliar a aquellas esculturas que no han conservado su parte superior, nos muestra la plasticidad y movilidad con que han sido concebidos los plegados por parte del artista, así como la existencia de un modelo único de togado para la elaboración de estas piezas. Por otra parte, en los togados $n^{\text {os }} 1,4,5,6$ y 8 podemos observar en su lateral derecho cómo los pliegues del sinus y de la ima toga se curvan y envuelven el cuerpo adaptán- dose perfectamente a la forma de la pierna derecha; así el tejido se adhiere a esta extremidad y nos permite observar cómo se halla flexionada por la rodilla y llevada un poco hacia atrás. Este elemento y el comentado anteriormente son argumentos que nos permite teorizar sobre la existencia de un único modelo para estas esculturas y, a la vez, su pertenencia a un mismo taller.

En relación a los aspectos técnicos y al acabado de estas esculturas, observamos que todos los togados, aunque mínimamente, conservan restos de la policromía ${ }^{9}$ con la que estuvieron cubiertos. Esta coloración, apreciable de visu, es de tonalidad ocre.

Tónica general en todos los togados es la utilización de piezas más pequeñas que quedaban acopladas con diversos sistemas y completaban las esculturas. Así, por ejemplo, en la $\mathrm{n}^{\circ} 1$, el balteus, y en las núms. 3 y 5 , el umbo, no conservados; en cambio, en la $n^{\circ} 2$ corresponde al lateral izquierdo de la mitad superior y en la $n^{\circ} 6$ al lateral izquierdo de la mitad inferior, donde aparece un pequeño rebaje cuadrangular. En la $n^{\circ} 4$ el tamaño de la parte acoplada es mayor, ya que corresponde a la mitad inferior del togado, a partir de las caderas. Por otra parte, este ensamblaje de piezas es habitual en la parte dorsal de los togados, posiblemente como consecuencia de su visión frontal ${ }^{10}$; en ocho togados $\mathrm{n}^{\mathrm{os}} 1,2,4,5,6,8,10$ y 11 - se conservan los restos del ensamblaje de piezas localizadas en distintas zonas de la espalda. El sistema más común para estos ensamblajes es elaborar una superficie rugosa e irregular para acoplar estas piezas, algunas veces combinada con los pernos —núms. 3,8 y 10 - y en el caso de la $n^{\circ} 8$ donde se utiliza el taladro; mientras, para la sujeción de manos y brazos se emplean siempre los pernos metálicos como en el togados $n^{\text {os }} 9$ y 10.

Los útiles empleados son siempre los mismos ${ }^{11}$; así destacamos el cincel dentado y el puntero para el acople de las piezas, salvo en el togado $n^{\circ} 8$, donde se emplea una técnica diferente con uso del taladro; la magistral labor del trépano para la realiza-

${ }^{9}$ La policromía aplicada al mármol está documentada desde los primeros momentos del mundo clásico (Retersward, 1960, 210-386, n. 162).

10 Recordemos que esta terminación posterior puede venir dada por una disposición adosada a la pared como en el caso de los togados del «Foro de Mármol» de Emerita Augusta hallados en hornacinas realizadas en el muro del pórtico de dicho foro (Álvarez-Nogales, 1988, 336-338).

1 Para el estudio de las técnicas de trabajo y de los útiles empleados por los talleres antiguos destacamos el trabajo clásico de Adam $(1966,2)$ con referencia a la bibliografía anterior, así como las publicaciones de Beltrán (1989), Pfanner (1989) y Rockwell (1989) y la obra de Nogales (1992, 368-391). 
ción del plegado, a la que nos hemos referido anteriormente, destacando los togados núms. 2 y 7 , ya que conservan sus huellas entre los pliegues del $\mathrm{si}^{-}$ nus y del balteus, respectivamente; y además la magnífica labor de alisado, cuyas pequeñas huellas presentan una disposición diagonal en la parte anterior e irregular en la parte posterior, en la que se observan especialmente ya que su terminación es menos cuidada y alguna vez inconclusa como en la pieza $n^{\circ} 11$, donde se aprecian la impronta del desbaste realizado con el puntero y el cincel.

Estas semejanzas en la labra, en los elementos técnicos e incluso en detalles concretos como el plegado de la túnica, nos permite plantear la hipótesis de un modelo único y también de una mano única. En la elaboración de esta serie de togados intervino un artista de grandes cualidades, que dirigió y trabajó directamente en la ejecución de cada escultura, de ahí sus importantes similitudes. Indudablemente este maestro tuvo a su cargo y bajo su dirección un equipo de escultores de gran preparación que contribuyeron a la realización de estas piezas. La presencia de distintas manos ha dejado su impronta en estos togados en pequeñas diferencias disimuladas por la enorme calidad de todas las piezas. En la estatua $n^{\circ} 1$ observamos el tratamiento de los plegados del umbo, del sinus y de la ima toga y, en general, podemos decir que estas zonas están dotadas de menor plasticidad en relación con el resto de esculturas: el umbo pende sobre el balteus de manera pesada y en gruesos plegados; los pliegues del sinus se disponen de manera irregular y no casi paralela como en las otras piezas, sólo los pliegues más gruesos vuelven sus aristas; la pierna derecha no acusa el ángulo de la ponderación de la escultura y la pesadez de la toga cubre la cadera izquierda. Por su parte, la estatua $n^{\circ} 3$ presenta un balteus formado por tres pliegues paralelos y simples, carentes de la movilidad y de los múltiples dobleces, producto de la maestría en el manejo del trépano de la estatua $n^{\circ} 2$; con calidad intermedia está el balteus de la $\mathrm{n}^{\circ} 7$. Entre estas diferencias, fruto de las manos que colaboraron en la realización de los togados, podemos mencionar la $n^{\circ} 11$. Aunque todas las esculturas, como hemos dicho más arriba, presentan una parte posterior ejecutada más superficialmente con pliegues espaciados y de poca profundidad, encontramos sólo un togado - el $n^{\circ} 11$ - en el que la parte inferior de los pliegues longitudinales que caerían desde el hombro izquierdo sólo ha sido representada como un listón, sin diferenciar dichos pliegues, a lo que se suma deficiente con abundantes huellas de la labor de desbaste.
El maestro de esta serie escultórica conocía a la perfección el modelo metropolitano de época de Claudio (Goette, 1990, 35-37); las características tipológicas y estilísticas de estas piezas participan de la regularidad de la producción de togados en todo el Imperio. Este conjunto también está inmerso en el fenómeno de proliferación de galerías de personajes imperiales togados que se colocan en los espacios públicos y prominentes de ciudades como Leptis Magna (Caputo-Traversari, 1976, 104, $\mathrm{n}^{\circ}$ 84-88, tav. 91-92). De igual manera, el maestro dominaba, con la familiaridad que da un largo periodo de formación ${ }^{12}$, el trabajo sobre el mármol, dotando a su creación de soltura y especialización. Sus avances le permiten recrearse en motivos y en el uso de las técnicas más avanzadas que dotan a cada una de estas obras y a su conjunto de calidad e individualidad.

En el apartado dedicado a la tipología hemos hecho referencia a otras galerías de togados de características tipológicas y estilísticas semejantes a estas piezas cordobesas, como los mencionados togados del teatro de Leptis Magna, aunque como conjunto más cercano y como producción de otro taller peninsular destacaremos los togados del «Foro de Mármol» de Emerita Augusta (Trillmich, 1993, 50-53, Abb. 7-9; 1996, 98-99), prueba también de la conexión y el contacto de los talleres de la Bética, en concreto de Colonia Patricia, y los de Emerita Augusta. Cinco togados aparecen firmados por C. Aulo y son la muestra del magnífico nivel de ejecución de las obras de uno de los principales talleres de la capital de la Lusitania.

A pesar de que poseemos un mayor número de piezas, once togados, del taller cordobés, éstas se conservan más fragmentarias, lo que contribuye a distorsionar, en cierta manera, las comparaciones entre estos dos conjuntos de togados y entre estos dos talleres de Emerita Augusta y de Colonia Patricia. La calidad es el denominador común en ambos conjuntos, pero a pesar de ello podemos apreciar ciertas diferencias en la ejecución y concepción de las piezas. En los togados cordobeses se plasma un desarrollo de la toga de manera más descriptiva y orgánica, con un plegado más minucioso, como observamos en los pliegues interiores del sinus; en cambio, en los togados emeritenses se busca el efectismo a través de la labor del trépano en pliegues escasos y amplios, sobre todo apreciables en el borde del sinus. De igual manera, la caída de la toga

12 Esta formación se remonta al periodo de finales de la República y principios del Imperio, donde los artistas y talleres locales se adaptaron perfectamente a la plástica y a los modelos oficiales, teniendo quizás como paradigma algunas obras importadas (León, 1990, 372). 
sobre el cuerpo se realiza en la galería cordobesa con gran plasticidad y naturalidad, los pliegues dibujan formas y volúmenes más pausados, sin olvidar los profundos efectos de claroscuro; existe un mayor cuidado por una composición de conjunto en la escultura. Se resalta y, a la vez, se cuida el modelado de las formas anatómicas, transparentadas por la toga, frente a los togados de Emerita Augusta que representan de una manera menos cuidada y global el cuerpo, especialmente la parte de las piernas bajo el sinus y la ima toga. La parte posterior presenta un buen acabado, con una superficie alisada, y una elaboración de los plegados que se detiene en la plasmación de los volúmenes de las caderas y los glúteos; en las esculturas emeritenses se observa un peor acabado, la superficie está menos alisada e incluso en ciertas partes apreciamos las huellas del puntero y del cincel.

Los rasgos observados hasta ahora permiten conceder un carácter local a este taller deudor, sin lugar a dudas, del aprendizaje junto a maestros urbanos venidos desde Roma que en época inmediatamente anterior (augustea y tiberiana) harían escuela de forma análoga a la documentada en la decoración arquitectónica (Márquez, e.p.).

\section{ICONOGRAFÍA}

Ya hemos comentado en otros apartados de este artículo la calidad de material y labra que poseen estos togados y sus semejanzas con ciclos dedicados a la familia imperial, como los procedentes de los foros de Leptis Magna (Caputo-Traversari, 1976, 104, n 84-88, tav. 91-92) y de Tarraco (Koppel, 1985,16 , Nr. 6-7, Taf. 6) y con la galería de summi viri del «Foro de Mármol» de Emerita Augusta (Trillmich, 1996, 98-99). La conservación en dos de estos togados -los $n^{\text {os }} 1$ y 2 - del hueco para la inserción de un retrato y la ubicación e identificación de los paralelos antes mencionados, nos induce a situar estas esculturas en uno de los foros o espacios públicos de Colonia Patricia, como soportes de los retratos de la familia imperial julioclaudia, o bien de «varones ilustres» ataviados con la toga picta o la toga triumphalis, de grandes duces como los representados en los pórticos del Forum Augustum de Roma y del «Foro de Mármol» de Emerita Augusta.

\section{BIBLIOGRAFÍA}

AdAm, S. (1966): The technique of Greek Sculpture in the archaic and classical periods, London.
Álvarez, J. y Nogales, T. (1990): «Schéma urbain de Augusta Emerita: le portique du Forum», Akten des XIII. Internationalen Kongresses für klassische Archäologie, Berlin 1988, Mainz, 336-338.

Baena, M. D. y Morena, M. J. (1989): «Estatua togada» en Arqueología Urbana, Córdoba, 46-51.

Beltrán, J. (1989): «El mármol en la Antigüedad Clásica. Una aproximación a su estudio», Gallaecia 11, 165-207.

Caputo, G. y Traversari, G. (1976): Le sculture del teatro di Leptis Magna, Roma.

García y Bellido, A. (1949): Esculturas romanas de España y Portugal, Madrid.

Goette, H. R. (1990): Studien zu römischen Togadarstellungen, Mainz-Rhein.

Koppel, E. (1985): Die Romischen Skulpturen von Tarraco, Berlin.

LEÓN, P. (1990): «Ornamentación escultórica y monumentalización en las ciudades de la Bética», Stadtbild und Ideologie, Die Monumentalisierung hispanischer Städte zwischen Republik und Kaiserzeit, München, 367-380.

LEÓN, P. (1993): «La incidencia del estilo provincial en los retratos de la Bética», Actas de la I Reunión sobre escultura romana en Hispania, Mérida, 11-21.

LEón, P. (1995): Esculturas de Itálica, Sevilla.

LóPEZ, I. M. (1996): «Estatua togada», en Vaquerizo, D. (ed.): Catálogo de la Exposición «Córdoba en tiempos de Séneca», Córdoba, 40-43.

LóPEZ, I. M. (1997): Estatuas togadas masculinas y estatuas femeninas vestidas de colecciones cordobesas, Tesis Doctoral inédita, Universidad de Córdoba.

Marcos, A. y Vicent, A. M. (1983): «Investigación, técnicas y problemas de las excavaciones en solares de la ciudad de Córdoba», Arqueología de las ciudades modernas superpuestas a las antiguas, Zaragoza, 231-252.

MÁrquez, C. (1991): «Desarrollo de los órdenes arquitectónicos en los capiteles de Colonia Patricia Corduba», MM 33, 113-132, Taf. 15-20.

MÁrquez, C. (1993): Capiteles romanos de «Corduba Colonia Patricia», Córdoba.

Márquez, C. (e.p.): «Modelos romanos en la arquitectura monumental de Colonia Patricia Corduba», AEspA 1998.

Moreno, M. F. (1995): Aproximación al estudio de la decoración musivaria en Colonia Patricia Corduba, Memoria de Licenciatura inédita, Universidad de Córdoba.

Nogales, T. (1992): Escultura romana emeritense: el retrato privado, Tesis Doctoral inédita, Universidad de Salamanca. 
Pfanner, M. (1989): «Über das Herstellen von Porträts. Ein Beitrag zu Rationalierungsmassnahmen und Produktionsmechanismen von Massenware im späten Hellenismus und in der römischen Kaiserzeit», JdI 104, 157-257.

Reuterswärd, P. (1960): Studien zur Polychromie der Plastik. Griechenland und Rom, Stockholm.

Rockwell, P. (1989): Lavorare la pietra. Manuale per l'archeologo, lo storico dell'arte e il retauratore, Roma.

RodA, I. (1996): «La escultura romana. Modelos, materiales y técnicas», Difusión del Arte romano en Aragón, Institución «Fernando El Católico», Zaragoza, 105-141.

Stylow, A. U. (1995): Corpus Inscriptionum Latinarum. Vol. $I^{2}$ : Inscriptiones Hispaniae Latinae.
Pars VII: Conventus Cordubensis, Berlin-New York.

Trillmich, W. (1990): «Colonia Augusta Emerita. Die Haupstadt von Lusitanien», Stadtbild und Ideologie, Die Monumentalisierung hispanischer Stätdte zwischen Republik und Kaiserzeit, München, 299-318, Taf. 22-29.

Trillmich, W. (1993): «Novedades en torno al programa iconográfico del Teatro Romano de Mérida», Actas de I Reunión de escultura romana en Hispania, Mérida 1992, 113-123.

Trillmich, W. (1996): «Reflejos del programa estatuario del Forum Augustum en Mérida», Actas de II Reunión sobre escultura romana en Hispania, Tarragona 1995, 95-108. 